The $B D J$ News section accepts items that include general news, latest research and diary events that interest our

readers. Press releases or articles may be edited, and should include a colour photograph if possible. Please direct your correspondence to the News Editor, Arveen Bajaj at the BDJ, The Macmillan Building, 4 Crinan Street, London N1 9XW or by email to bdj@bda.org

\section{Fellowship awarded}

Kevin Lewis, Director of Dental Protection, has been awarded a Fellowship in Dental Surgery from the Faculty of Dental Surgery of the Royal College of Surgeons of England.

The award recognises the contribution that Dr Lewis has made to dentistry both in the UK and around the world. Before joining Dental Protection, he had established a successful preventive practice in Peterborough while at the same time developing his writing and lecturing skills.

Commenting on the award, Dr Lewis said, 'I am extremely fortunate to have had so many opportunities to serve my profession in such interesting ways throughout my professional career - none of which I could have foreseen at the time I graduated. Hopefully this award will encourage others to seize whatever opportunities come their way, and to make the best of them.

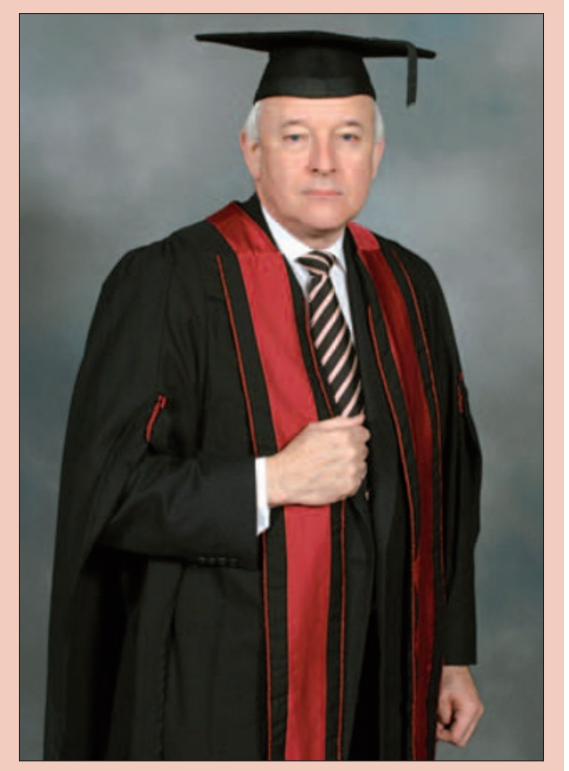

\title{
Biofilm in 3D glory
}

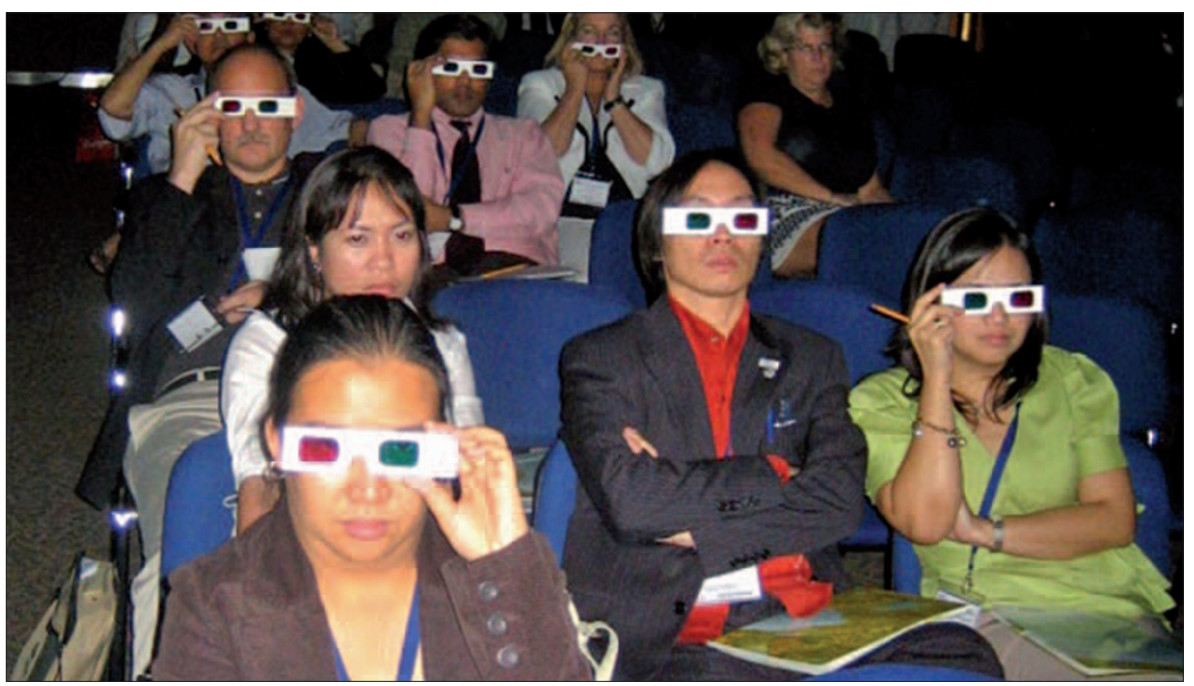

Delegates at the recent FDI Congress in Dubai view 3D images showing the complexity and sophistication of dental plaque biofilm (above). Delegates were asked to use the 3D specs to view images by Professor J G Thomas from West Virginia University, USA, who used the technique during the Listerine sponsored symposium. He commented that it was a great adjunct to his talk and allowed the audience to have enduring images that they could take away with them.

\section{Stopping hair loss with good oral health}

There is a close relationship between dental disease and hair loss, according to researchers from the Department of Stomatology at the University of Granada, (UGR) Spain. Professors José Antonio Gil Montoya and Antonio Cutando Soriano, advise visiting the dentist when patients notice the presence of alopecia areata, or localised alopecia, a type of hair loss which has an unknown origin but which is thought to be auto-immune in nature.

Alopecia areata starts with bald patches on the scalp, and sometimes elsewhere on the body. The disease occurs in people of all ages, and experts believe that it affects one in 1,000 people. According to the Professors at the UGR, the affected hair follicles are not totally destroyed. Therefore the hair can grow back - hair re-grows in most patients after several months, although in a quarter of all patients the condition recurs once or more.

The researchers noticed that some outbreaks of localised alopecia appeared to be associated with dental infections. They explained, 'We have found that bald patches caused by tooth infection are not always in the same place. They normally appear on a line projected from the dental infection and can thus can be located on the face at the level of the maxillary teeth, above a line through the lip-angle to the scalp, beard, or even to the eyebrow. Nevertheless, they can also be located far from infection outbreak.'

They advise patients with alopecia areata to visit their dentists in order to receive a careful examination of their oral health. 


\section{An evidence-based toolkit for prevention launched}

An evidence-based toolkit for prevention was launched recently in Liverpool by Barry Cockcroft, Chief Dental Officer for England as a result of work conducted by a number of organisations.

The way in which dentistry is delivered in the UK has shifted emphasis from mainly treatment to a more preventive model of care, and to assist and support PCTs and dental teams in the delivery of a more preventive approach, the Department of Health commissioned the British Association for the Study of Community Dentistry (BASCD) under the Chairmanship of Sue Gregory (President 2006-2007), to develop a simplified prevention guide for primary dental care. The guidelines that arose from this work provide clear and simple messages based on the current available research evidence.

The launch was organised by Dr Lesley Gough, Clinical Director, at Everton Road Health Centre, Liverpool. Amongst the attendees were Dr Jackie Duxbury, Dr Melanie Catleugh and Dr Gill Davies who all made a contribution to the production of the toolkit.

Dr Sue Gregory said, 'The toolkit provides clear messages in an easy to use format. It is designed for all members of the dental team to help them convey consistent, evidence-based preventive messages to patients. In addition, it is very useful for healthcare professionals and members of the public who may wish to check up on the latest advice around fluoride availability, healthy eating and sugar-free medicines.'

To view the document visit www. dh.gov.uk.

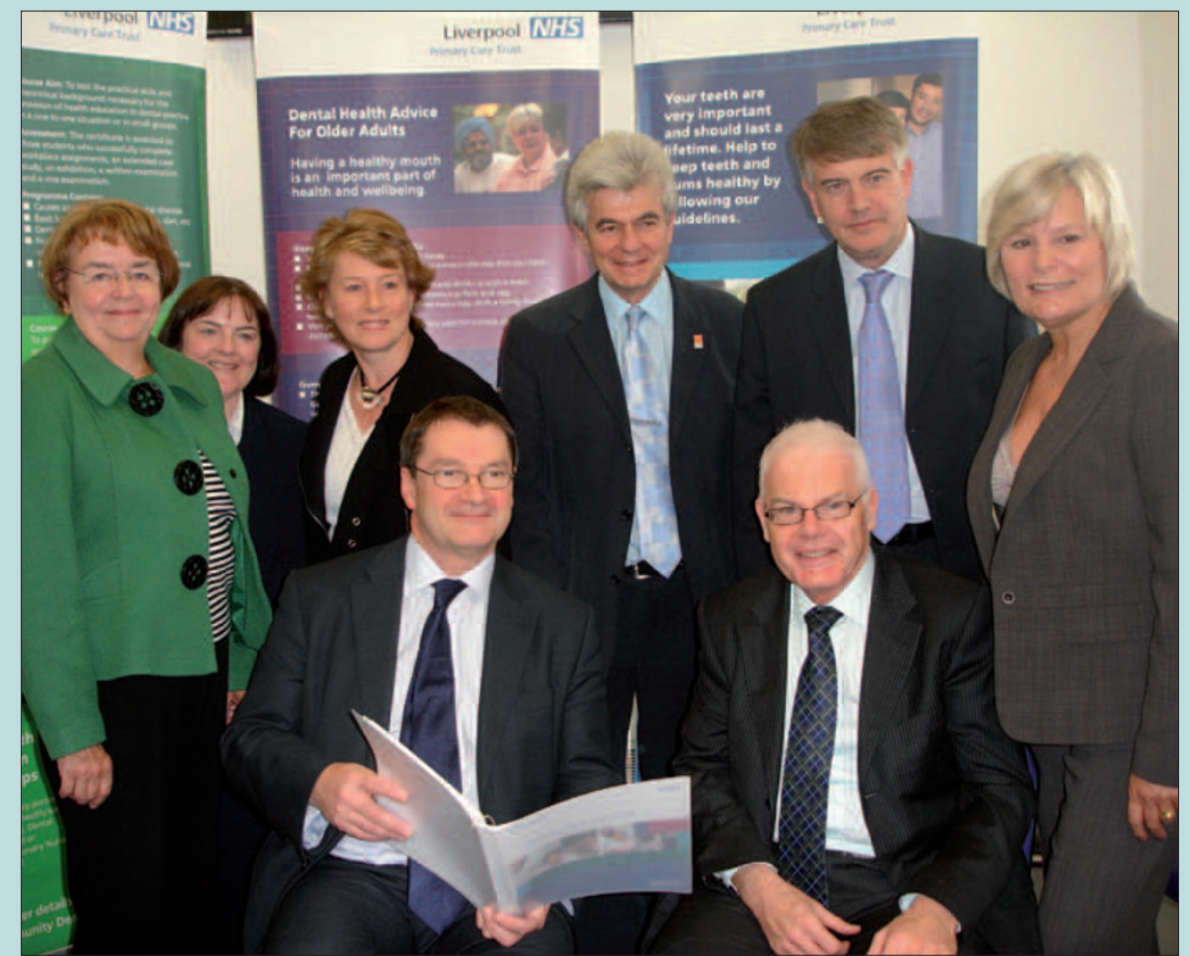

Left to right, standing, Jackie Duxbury, Melanie Catleugh, Gill Davies, Gideon Ben-Tovim, Tony Jenner and Sue Gregory. Left to right, sitting, Barry Cockcroft, Derek Campbell

\section{Patient care highlighted in dental awards}

Members of the dental community, including dentists, dental care professionals and other stakeholders were recognised recently at the second annual British Dental Association (BDA) Honours and Awards Dinner in London, sponsored by the British Dental Trade Association.
The Chipping Manor Dental Practice from Wotton-under-Edge, Gloucestershire, was named as the first winner of the Good Practice Scheme Practiceof-the-Year Award. The award, open to all members of the BDA Good Practice Scheme, recognises outstanding

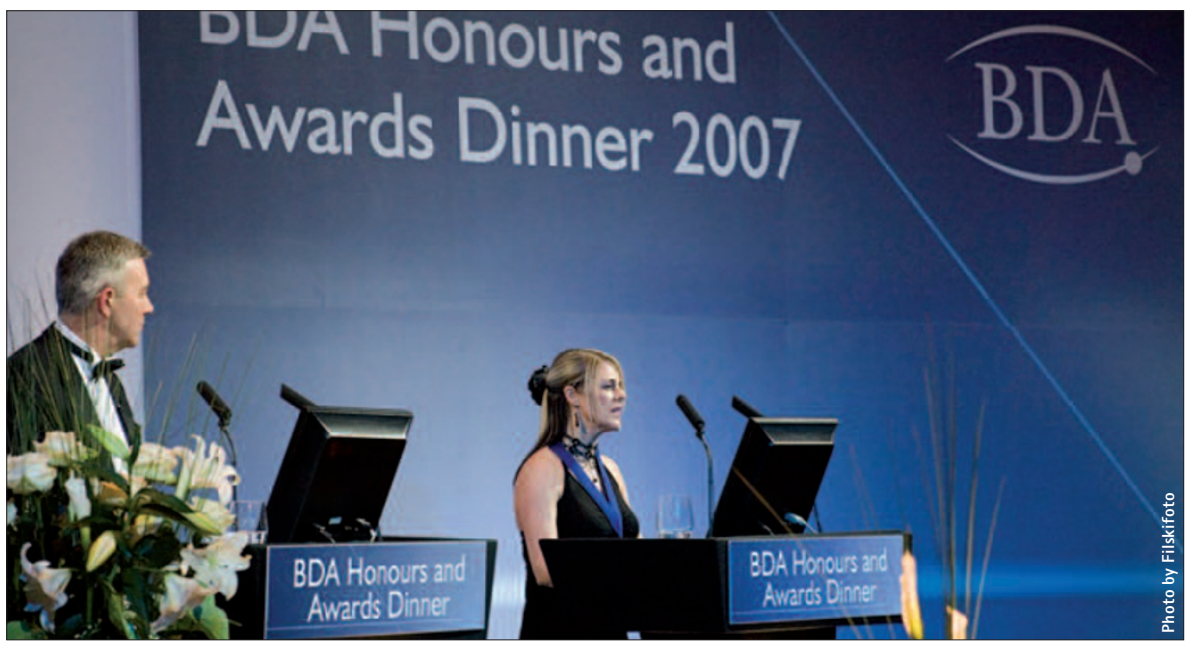

commitment to patient care by the whole dental team.

The honours and awards presented included BDA life membership to Peter Bainton, John Black, Stanley Gelbier and Douglas Pike, while BDA Fellowships were awarded to Ralph Davies, Pat Denning and Ellis Paul.

The 2007 British Association of Dental Nurses Award was presented to Paula Sleight, entry on the British Association of Dental Therapists Roll of Distinction was conferred upon Tracy Thompson, and the British Dental Practice Managers' Association Executive Award was presented to Chrissie White.

The British Dental Trade Association Award was presented to Norman Freedman while entry on the BDA Roll of Distinction was conferred upon Hilary Cook, Hugh Edmondson, John Taylor and the late Julia Campion.

The BDA John Tomes Medal was presented to Jim McDonald and the Dental Technologists Association Award was presented to Tony Griffin. 


\section{Christmas cover artwork offer for $B D J$ readers}

$B D J$ cover artist Joe Dixon is offering $B D J$ readers a fantastic opportunity to purchase original paintings from his series produced for $B D J$ volume 202 at a special Christmas price.

The available paintings, in acrylic on paper and depicting micro-organisms of dental and oral importance, are
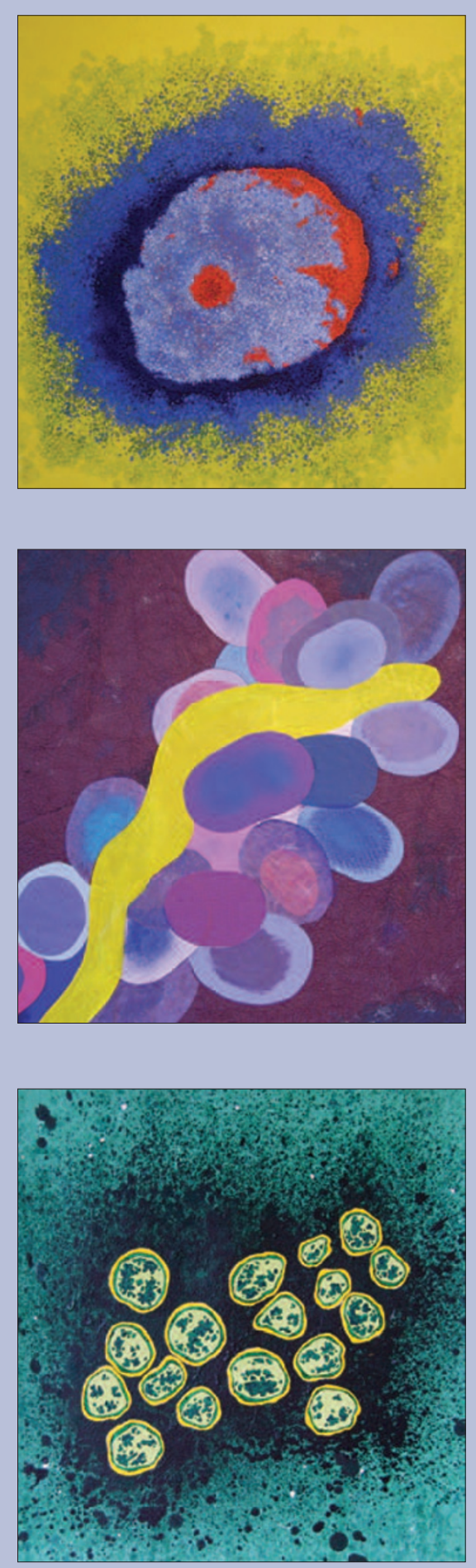

entitled Candida albicans, Herpes simplex, Streptococcus mutans, Hepatitis C, Porphyromonas gingivalis, Lactobacillus, Staphylococcus aureus and Treponema denticola. Each measures $45 \times$ $45 \mathrm{~cm}$ including a dark wood frame.

The paintings are all shown here and are available at a one-off Christmas price of $£ 275$ each.

If you are interested in purchasing a painting or would like any more information, please contact the artist, Joe Dixon, at joedicko@hotmail.com.

The pictures can also be viewed online at www.jdarts.co.uk.

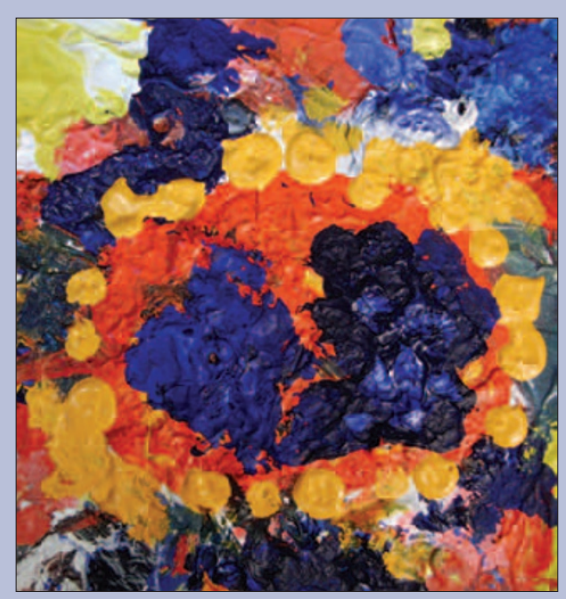

The available paintings: top - Herpes simplex (left) and Candida albicans (right); middle row (left to right) - Streptococcus mutans, Porphyromonas gingivalis and Treponema denticola; bottom row (left to right) - Hepatitis $C_{\text {, }}$ Lactobacillus and Staphylococcus aureus
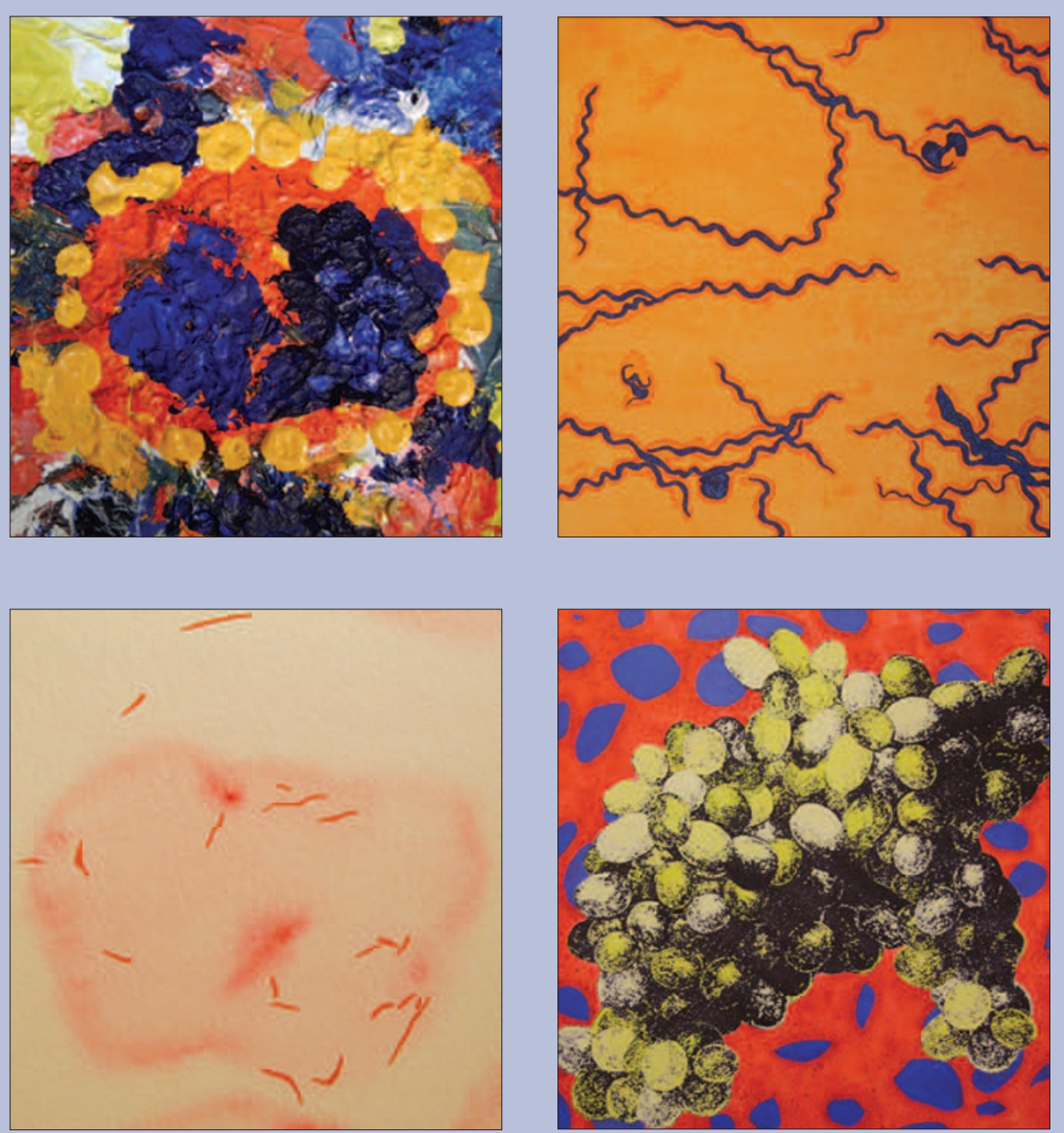


\section{DIARY}

January

Achieving high standards

in infection control

Date: 25 January 2008

Venue: BDA, London

www.bda.org/events

February

Preparing for retirement Date: 1 February 2008

Venue: Aldwark Manor Hotel, York

www.bda.org/events

143rd Chicago Dental

Society Midwinter Meeting

Date: 21-24 February 2008

Venue: McCormick Place Lakeside Center,

Chicago, USA

www.cds.org/mwm

\section{Children seen by NHS dentists}

Just over 70\% of all children in England have seen an NHS dentist in the last two years, a report for the Information Centre for health and social care (The IC) has revealed. The report, 'NHS Dental Statistics for England, Quarter 1, June 2007' showed 54.9\% (27.9 million) of the population was estimated to have been seen in the two years leading up to 30 June 2007. Of those, 7.8 million were aged 17 or under $-70.7 \%$ of all children. NHS dentists saw 50.5\% of all adults (20.1 million) during the same period. The report, which considers NHS dental activity in England and includes analysis of the number of courses of treatment, found the proportion of people seen varied by Strategic Health Authority (SHA) area.

The highest proportion of children seen (73.9\%) was in the North East SHA, while London SHA saw the lowest proportion $(65.5 \%)$. The highest proportion of adults seen (59.5\%) was in the North East SHA area and the lowest proportion (40.0\%) in the South Central SHA area. For further information visit www.ic.nhs.uk.

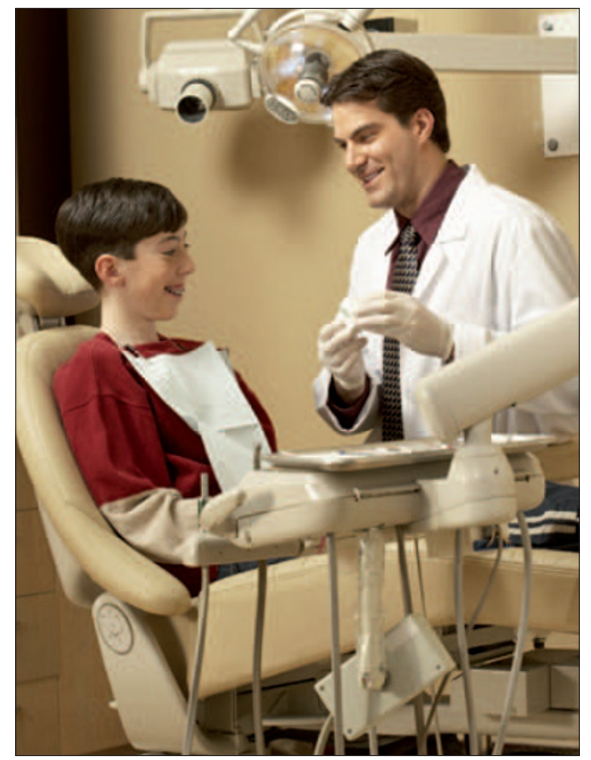

\section{Birmingham school scoops higher education award}

A team of staff from the University of Birmingham's Dental School are celebrating after winning a prize at the Times Higher Education Supplement Awards, which took place in London earlier this month.

Giles Perryer, Ecourse Developer and Lecturer in Clinical Practice, Dr Deborah White, Director of Learning and Teaching and Head of Dental Public Health, and Professor Damien Walmsley, Chairman of ICT Committee and Professor of Restorative Dentistry, won the Outstanding ICT Initiative of the Year prize, sponsored by the Joint Information Systems Committee (JISC).

The prize was awarded for the school's newly developed content management system, which complements traditional learning and teaching environments and materials. The new system allows students to create their own content online as well as giving staff a way of delivering interactive learning and teaching materials. This includes a range of educational podcasts, which are available through iTunes, and video for clinical problems at short notice.

Thejudges were particularly impressed content, which helps students prepare by an innovation of the microscopic kind. Recently the school's content management system has been enhanced further by the development of a component-free virtual microscope, allowing students to view slides remotely.

The virtual microscope recognises what features are on a slide, and guides students to zoom in on areas of specialist interest. The system will also allow staff to create virtual patients with a variety of dental conditions to simulate the experience of testing and applying knowledge in the clinic.

Giles Perryer explained that the School has a diverse student body, who are based away from the University's main campus and also spend a significant period of time in clinics, making interactive learning particularly important.

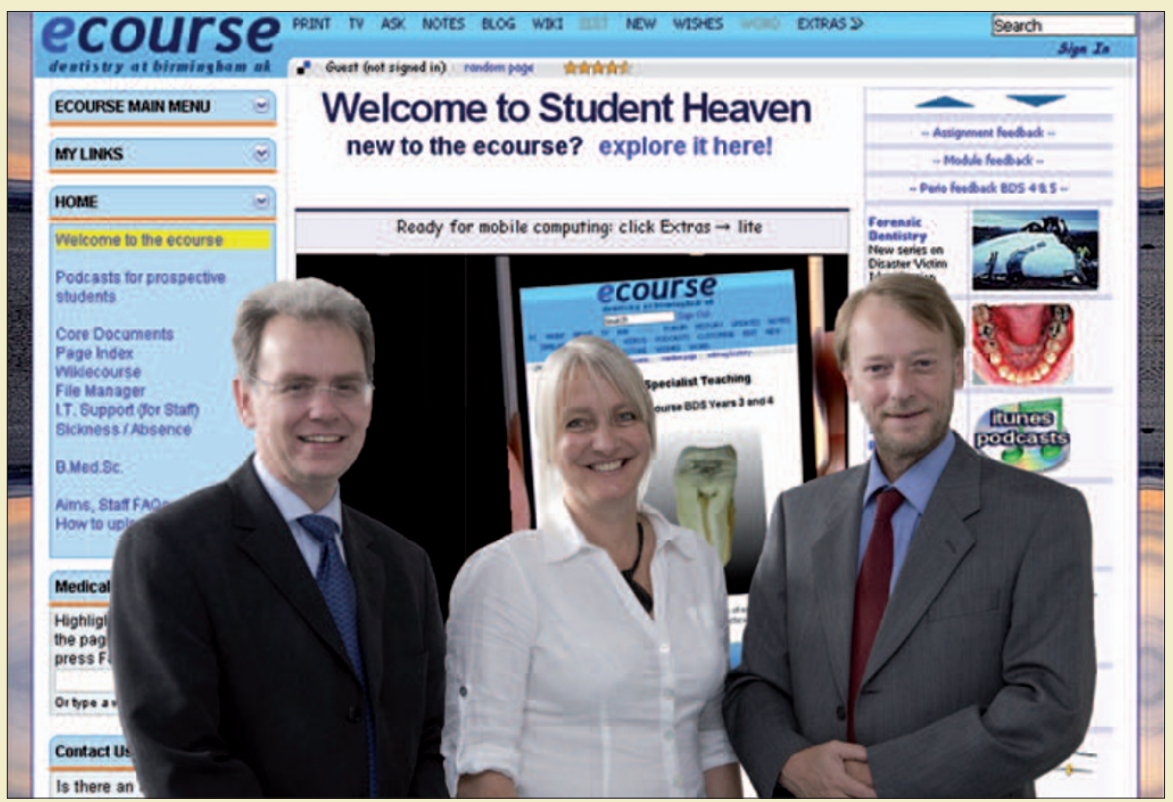

Damien Walmsley, Deborah White and Giles Perryer with the award winning Ecourse in the background 